Evaluation

At the end of each course the participants' views were obtained by means of a questionnaire which could be anonymous. In response to a question asking the trainees who had personally employed behavioural treatment during the course if it had been effective in their opinion, six said yes, one felt that while the psychological treatment had been beneficial it was best employed in conjunction with medication, and one was equivocal. Although, in general, positive attitudes were expressed about the course, one participant found the structure too 'fragmented' with insufficient 'flow' from one week's topic to the next. Another advocated the inclusion of 'practical treatment demonstrations', and complained that the sessions were not long enough. One appreciated the use of role play in the marital therapy seminar and thought this technique should have been more widely exploited. Distribution of handouts well in advance of seminars was suggested by another, and to show it is difficult to please all of the people all of the time one said the sessions should be more 'didactic and directive'. All except one stated that they were more likely to use behavioural psychotherapy in the future. The exception (who intends to work ultimately as a psychoanalyst) said he was more likely as a result of the course to refer certain patients to clinical psychologists for behavioural treatment.

\section{The non-medical participants}

Of the five nurses, four had direct involvement in supervising ward-based programmes during the course. Also two assisted in the treatment of agoraphobic patients and one in treating a patient with obsessional thoughts. Both occupational therapists acted as co-therapists in social skills training groups. The research psychologist had much more previous experience than the other participants and provided usefully informed input during sessions.

All the non-medics commented positively on the course and several thought increased interdisciplinary understanding had resulted. The nurses particularly appreciated a discussion of operant conditioning as a theoretical rationale for ward-based programmes while the occupational therapists thought that social skills training should be an important aspect of their work.

\section{Comment}

Having received feedback from participants on other courses we have run in this department, it was evident that this course was particularly well received. Further twiceyearly courses are planned incorporating where possible suggestions from previous participants. For instance there will be more emphasis on the use of behavioural psychotherapy in combination with drug treatment. Also we hope to make greater use of videotaped recordings to illustrate teaching points and to enable more direct feedback on the treatment of patients.

Our impression is that certain popular misconceptions about behavioural treatment can be dispelled during courses of this kind and first-hand experience of using behavioural methods seems important for this. Certainly, personal involvement in the treatment of patients by all participants while the course is running will be our aim in the future.

Clearly, systematic assessment of courses of this kind is necessary. As well as attitude change and the extent of any subsequent use of behavioural methods, the appropriateness of referrals to the clinical psychology department for treatment is an outcome variable we intend to look at.

\section{REFERENCES}

'MAaks, I. M. (1981) Psychiatry and behavioural peychotherapy. British Journal of Psychiatry, 139, 74-78.

${ }^{2}$ WATTS, F. N. (1985) Clinical psychology. Health Trends, 17, 28-30.

${ }^{3}$ The Royal Collage of Psychatrists (1971) Guidelines for the training of general psychiatrists in psychotherapy. British Journal of Psychiatry, 119, 555-557.

4Marks, I. M. (1982) Toward an empirical clinical science: behavioural psychotherapy in the 1980s. Behaviour Therapy. 13, 63-81.

\title{
The Mental Health Act 1983 Draft Code of Practice Mental Health Act Commission's Discussion Paper on Consent to Treatment
}

\author{
LORD Colville, Chairman, Mental Health Act Commission
}

Professor Bluglass ${ }^{1}$ has recently written in the Bulletin on this subject. Articles have also appeared in the British Medical Journal by Dr Hamilton ${ }^{2}$ and Professor Kendell. ${ }^{3}$ Comments were invited on both documents: to the DHSS on the Code and to MHAC on their paper. To judge by the articles referred to, clarification of the background to and function of both documents is urgently needed.
Neither the Royal College of Psychiatrists nor any other professional body has, to date, produced a Code of Practice for those concerned with mental health. Parliament required that a Code should be written. Presented with this task the Commission considered what should be done. A brief statement of uncontentious principles, susceptible of no disagreement, seems to be that for which some are now 
hankering; and the Commission considered this. However, the Act spells out very clearly the wide range of professional people who are to be addressed. It is the Act, not the Commission, which says that 'medical treatment' includes 'nursing and also care, habilitation and rehabilitation under medical supervision'. Moreover commitments were made in Parliament during the Bill's passage about matters to be included. It is regrettable that Professor Bluglass did not enunciate his 'basic principles' earlier; he was a member of the Commission throughout the preparation of the Draft. What was decided at that time was the construction, not of a bedside booklet for quick reading, but a manual for use in difficult circumstances: an answer to the legion of tricky questions which Commissioners have been asked on visits to hospitals and elsewhere. Amendments will, of course, be needed. No draft is perfect. However it would be interesting to assess some brief alternative version, incorporating nothing but a concensus view. Would it do the job that has been prescribed? Is there, indeed, a degree of consensus between the different professions concerned? Do these contributors not wish even to discuss the difficult problems where good practice might usefully be worked out?

Thus a major policy decision will have to be made by the Secretary of State; whether the Commission has, as the complaint now goes, exceeded its remit. He and his advisers know better than anyone what Section 118 was intended to cover, for that is as much a matter of policy as of legal interpretation. However there is another issue on which doubt remains: how is the Code to be used? Parliament increasingly provides in statutes for a code of practice. Since the debate in the House of Lords on 5 January 1986, which Professor Bluglass dissects, much attention has been given to the exact purpose of codes in several pieces of new legislation. Yet in the other Acts there was not always precision.

The Highway Code, which seems the favourite subject of comparison, has a clear position. A failure to observe one of its provisions may be relied on in civil or criminal proceedings as tending to establish or negative a liability which is in question. With that purpose in mind and concerned with conducting mechanical vehicles along the roads its contents are susceptible to concise precepts commanding universal consensus. Stricter still are the rules in the Codes under the Police and Criminal Evidence Act 1984, since a police officer is liable to disciplinary proceedings for a failure to comply with them (Section 67(8)). By contrast the 'guidance' issued by the Department of Transport about making access to buses easier for disabled people-(Transport Act 1985, Section 126(7))-cannot carry any legal implication. The Mental Health Act code must fall somewhere in the middle. Dr Hamilton remarks that I said (in the House of Lords debate) that failure to comply with its terms might be held relevant in disciplinary proceedings, or a negligence action. So I did, but I added a plea never again to leave matters so imprecise. Failure as such can surely not be the foundation for disciplinary proceedings (as for the police); nor perhaps would it tend to establish or negative any liability. Yet, like any authoritative textbook, it may have its place in considering professional conduct, though only to the extent that it may be relevant to the facts of the case. Its prime purpose, however, seems to be to give 'guidance' to professional people, dealing with each other, ill patients and their families: a more complex assignment, I think, than that confronting the draftsman of the Highway Code.

Not being intended as a bedside book, it has a very full index. As do other Codes, it refers where necessary to the law, which in this consolidation Act is not always easy to follow. No doubt Professor Bluglass, as a member of the group which wrote the Chapter on Admissions through the Courts, would endorse this.

In their articles both Dr Hamilton and Professor Kendell refer to the Chapter in the draft Code on Consent to Treatment, and to the MHAC's discussion paper on that subject. They do not differentiate with any clarity between the two; this is regrettable since the two documents have distinct purposes.

Both were written by a group of Commissioners, including doctors, who had the advantages of their professional backgrounds, and who had been faced, on Commission visits, with numerous queries, generally from doctors on difficult issues about consent. These were no matters of theory, but the hard reality of decisions about patients. The draft Code accordingly set out to suggest as many answers as possible. Any Code of course to be consistent with existing decisions of the courts. But since 'good practice', in difficult situations, cannot be seen to run counter to the likely way in which the courts would decide in those situations, the Code has had to interpret how the courts would so decide. The hope was that, far from adding to the problems, this would enable doctors and other professional people to find their way through the difficulties. It could also give some protection, since, once approved, the Code will contain 'guidance' on which they may reasonably put some faith. At the very least it will merely correspond with the existing rules. It is hard to see why that should be damaging to treatment or to research, unless of course these rules are currently not complied with.

The discussion paper has a separate function. The existing law does not contain a provision for all contingencies. For example the Declaration of Helsinki dealing with research, including that of a clinical, therapeutic nature, envisages national legislation to deal with the impossibility of obtaining consent because of physical or mental incompetence (Basic Principles, 11). There is none in the UK. Like all other projects on law reform issued in recent years the paper sets out the quandary and suggests possible answers, to facilitate research and at the same time look after the incapable patient's interests. As is normal comments are invited. Of the hundred or so such responses to date, it is clear that most readers have fully comprehended that position; $90 \%$ have been complimentary, or very much so, but many have also put forward highly constructive proposals to improve the text. The $10 \%$ who were seriously critical put forward nothing to replace the paper. Professor Kendell says that if the guidelines were accepted (I think he is referring to the Draft Code rather than the discussion paper) 
clinical research into dementia would virtually cease. If so, in the light of the present law (as, we hope, set out in the draft), the Nuremberg Code and the Declaration of Helsinki, it is to be wondered how it currently proceeds at all. Wishful thinking will not ensure that these dilemmas will just creep away.

These two articles do, however, create further confusion by stating that terms such as 'clinical' or 'therapeutic' research are not defined. No doubt, however, the authors are as familiar as were the writers of the discussion paper with the difference between Part II (Clinical research, including diagnostic and therapeutic methods) and Part III (Non-clinical Biomedical Research) of the Helsinki Declaration. This is the product of the World Medical Association, on which it should be safe to rely. For the avoidance of doubt it would be easy to quote: 'In the field of biomedical research [involving human subjects] a fundamental distinction must be recognised between medical research in which the aim is essentially diagnostic or therapeutic for a patient, and medical research, the essential object of which is purely scientific and without direct diag- nostic or therapeutic value to the person subjected to the research'. But perhaps the text of the Code should not be made still longer.

The Commission does not seek confrontation with the psychiatrists over the Draft Code or the discussion paper. We would readily concede that the text can be improved. I hope that this article will explain more clearly the "job description' which has been specified by us for each document; and thereby direct more accurately attempts to improve it both in principle and detail.

\section{REFERENCES}

'Robert Bluglass (1986) The Draft Code of Practice (Mental Health Act 1983)-in pursuit of agreement. Bulletin of the Royal College of Psychiatrists, 10, 76-78.

${ }^{2}$ JoHn R. Hamilton (1986) Code of Practice for the Mental Health Act 1983: "Patronising and unrealistic". British Medical Journal, 292, 1219-1220.

${ }^{3}$ KendeLL, R. (1986) The Mental Health Act Commission's 'Guidelines: a further threat to psychiatric research'. British Medical Journal, 292, 1249-1250.

\section{Obituary}

\section{IAN Henderson (Mental Health Foundation)}

The death of Mr Ian Henderson was announced in May 1986. In 1949, Ian Henderson, together with Dr Derek Richter, founded the Mental Health Research Fund, later to become the Mental Health Foundation. Throughout the ensuing 37 years, Ian Henderson remained active in the Fund and Foundation and was one of the driving forces behind its success. He saw it grow from a small organisation which held the occasional conference and raised modest sums of money for psychiatric research, to a large foundation disbursing over a million pounds a year, not only for scientific purposes but also for developing and evaluating treatments and services.

Ian Henderson was always intensely interested in the work of the Foundation and gave generously of his time and energies. His presence at its meetings will be sorely missed. Psychiatrists owe him a great deal.

\section{Kenneth Macrae, Emeritus Professor of Forensic Psy-} chiatry, University of Edinburght

Professor Kenneth Macrae, who died on 13 February 1986 at the age of 68, will be remembered as the first Professor of Forensic Psychiatry at the University of Edinburgh and the Physician Superintendent of the State Hospital, Carstairs for 10 years until he retired in 1979. Kenneth Macrae was born and educated in Scotland and qualified at Edinburgh in 1941. The following year he became a Medical Officer in the RAF where he served for four years, progressing to the rank of Squadron Leader and being awarded the AOC's Certificate of Merit. After completing his house jobs he took up psychiatry in 1948, taking the diploma in psychiatry in 1951. In December of that year he was appointed Deputy Physician Superintendent of Dingleton Hospital, Melrose and in 1954 became, at a relatively young age, the Physician Superintendent of Bangour Village Hospital, West Lothian. In his 15 years in that position Kenneth strove to reduce patient numbers and bring the hospital into line with current philosophies of care.

His administrative experience led to his becoming a member and later Vice-Chairman of the South East Regional Hospital Board, a member of the Scottish Probation Advisory and Training Council and of the Standing Medical Advisory Committee. He became a member of the Royal Colleges of Physicians of both Edinburgh and Glasgow. He was Secretary of the Scottish Division of the RMPA from 1963 to 1967 and was elected the Division's Chairman in 1967. He was elected a foundation Fellow of the College and later served on the Public Policy Committee and the Mental Health Act Working Party.

Kenneth Macrae had long had a keen interest in forensic psychiatry and lectured on the subject at Edinburgh University from 1956. He had also been the leading expert in the south-east of Scotland called on by the Crown in important trials to give evidence on the mental state of the accused. With this background he became the natural choice in 1969 to fill the newly-created combined post of Professor of Forensic Psychiatry at Edinburgh University and Physician Superintendent of the State Hospital, Carstairs. Over the years Kenneth constantly endeavoured 